\title{
Eradication of feral goats Capra hircus from Pinta Island, Galápagos, Ecuador
}

\author{
Karl Campbell, C. Josh Donlan, Felipe Cruz and Victor Carrion
}

\begin{abstract}
Introduced mammals are a major driver of extinction and ecosystem change, particularly on islands. Feral goats Capra hircus have been introduced to numerous islands worldwide and have had wholesale impacts on ecosystems. Techniques are now available, however, to eradicate goat populations from islands, providing a powerful conservation tool. Goats were removed from Pinta Island, Galápagos, Ecuador after a 30-year eradication campaign, the largest removal of an insular goat population using ground-based methods. Over 41,000 goats were removed during the initial hunting effort (1971-82). In the following decade the island was twice wrongly declared free of goats. During this period, the island was visited irregularly but no monitoring programme was implemented. A revised campaign over
\end{abstract}

1999-2003, which included improved hunting techniques and monitoring, removed the final goats from the island. The use of Judas goats was critical in locating the remaining goats and as a tool to confirm eradication. A systematic monitoring programme is critical for confirming eradication and preventing future reintroductions. An earlier monitoring programme would probably have resulted in earlier eradication and significant financial savings. Given limited resources, island conservation programmes elsewhere should strive to increase eradication efficiency and learn from past campaigns.

Keywords Capra hircus, eradication, exotic species, Galápagos, Geochelone nigra, goats, Judas, Pinta Island, tortoises.

\section{Introduction}

Extinction over the last 6 centuries has been largely dominated by insular species, with non-native mammals being responsible for the majority (Diamond, 1989; Groombridge et al., 1992; MacPhee \& Flemming, 1999). Island vertebrates and plants are particularly vulnerable to the impacts of rats Rattus spp., feral cats Felis catus and introduced herbivores (Elton, 1958; King, 1985; Davis et al., 1986; Ebenhard, 1988; Ceballos \& Brown, 1995; Daltry et al., 2001; Tershy et al., 2002). Feral goats Capra hircus have been introduced to at least 397 islands worldwide (K. Campbell, unpub. data), resulting in primary and secondary impacts via overgrazing, often leading to extinctions and habitat destruction (Coblentz, 1978; Cruz \& Cruz, 1987; Schofield, 1989; Moran, 1996; Desender et al., 1999).

Karl Campbell ${ }^{1}$, Felipe Cruz $^{1}$ and Victor Carrion Galápagos National Park Service, Puerto Ayora, Isla Santa Cruz, Galápagos, Ecuador.

C. Josh Donlan² (Corresponding author) Department of Ecology and Evolutionary Biology, Corson Hall, Cornell University, Ithaca, New York 14853-2701, USA. E-mail cjd34@cornell.edu

${ }^{1}$ Also at: Charles Darwin Foundation, Casilla 17-01-3891, Quito, Ecuador.

${ }^{2}$ Also at: Island Conservation, Center for Ocean Health, University of California, 100 Shaffer Road, Santa Cruz, California 95060, USA.

Received 25 June 2003. Revision requested 30 September 2003. Accepted 26 November 2003.
Over the last 30 years techniques have been developed to eradicate feral goat populations from islands (Daly, 1989; Veitch \& Clout, 2002). These techniques, which include both ground and aerial hunting campaigns, as well as the use of Judas goats, have resulted in the successful eradication of goats from $>100$ islands worldwide (K. Campbell, unpub. data). The use of Judas goats, radio-collared individuals that are released and associate with conspecifics, aid in removing goats at low densities (Taylor \& Katahira, 1988; Rainbolt \& Coblentz, 1999). Unfortunately, the majority of eradication efforts remain unpublished, and as a result such knowledge is often unavailable to conservation practitioners (Simberloff, 2001; Donlan et al., 2003).

Here, we report on the 30-year eradication campaign of goats from Pinta Island in the Galápagos Archipelago, Ecuador, the largest insular goat population removal using ground-based methods to date. Over 41,000 goats were removed from Pinta during an initial hunting campaign. In the decade following, the island was twice wrongly declared eradicated (Calvopiña, 1985; Evans, 1990), highlighting the need for regular monitoring programmes. Revised hunting techniques and a monitoring programme were implemented in 1999. With this programme in place, the island is now free of goats.

Pinta Island (5,940 ha), located in the northern part of the Galápagos archipelago, enjoys protected status and receives little visitation by scientists or managers and 


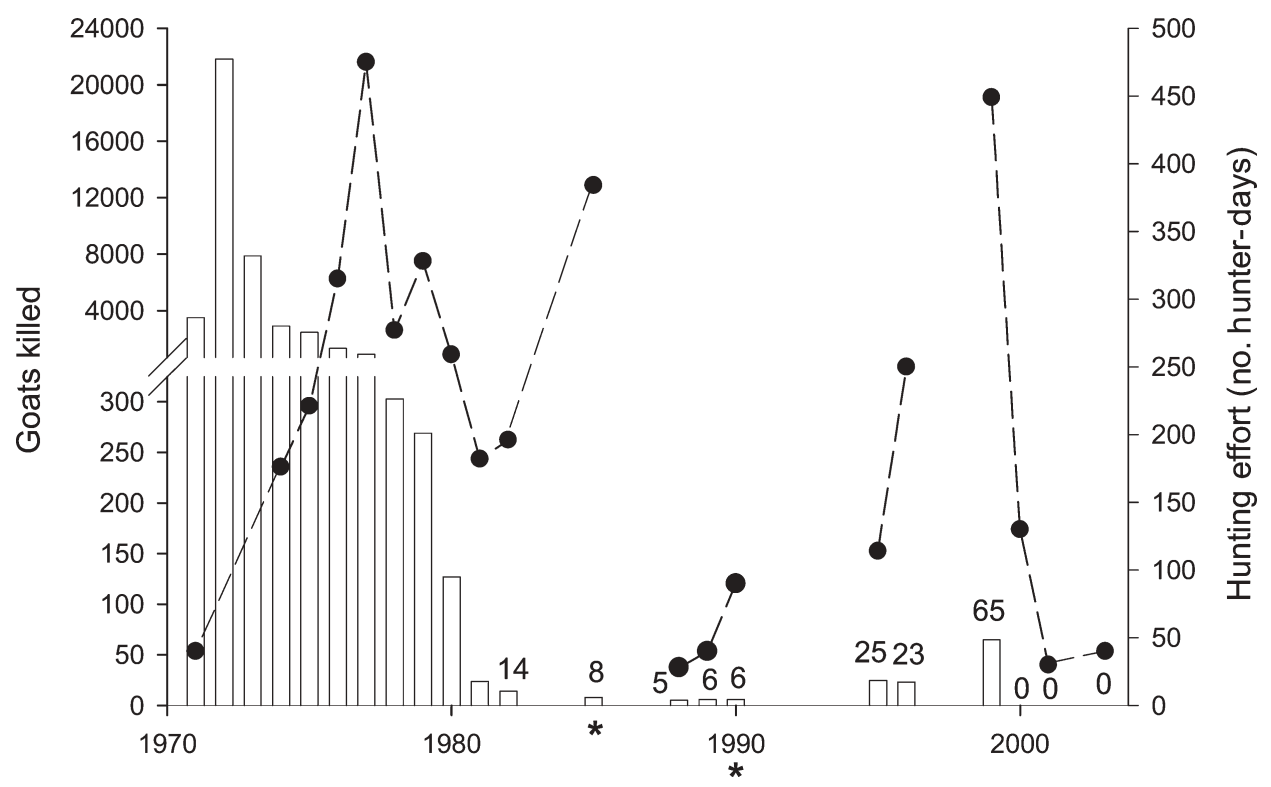

Fig. 1 Pinta Island goat eradication, 1971-2003. Bars represent number of goats killed per year. Points represent the annual effort (number of hunter-days, includes both hunting and logistical days). For example, in 1995, 23 goats were killed in 250 hunter-days and the following year (1996) no hunting took place. The island was falsely declared goat free in 1985 and 1990 ( $^{*}$. Effort from the 2003 tortoise search is not included. Judas goat techniques were implemented in 1999 (see Table 1). The number of goats killed in the 1970s might be inflated, see text for further details.

none by tourists (Snell et al., 1995). With $59 \%$ of the island vegetated and a maximum elevation of $650 \mathrm{~m}$, this isolated island contains high levels of plant diversity and endemism (>180 species, 59 Galápagos endemics; Hamann, 1981). There are no native land mammals, a number of endemic bird species, and previously two endemic terrestrial reptiles: the lava lizard Microlophus pacificus and the giant Galápagos tortoise Geochelone nigra abingdoni. The latter is extinct in the wild. The tortoise population, once numbering in the thousands, was decimated in the 19th century by whalers and other seamen who collected tortoises for meat (de Vries, 1984). Scientific collecting in the early 1900s reduced the population even further (Van Denburgh, 1914; Pritchard, 1984). Goats were introduced onto the island in the late 1950s, most likely in 1959 (Hoeck, 1984). By 1971 the goat population was at least 20,000 individuals (Weber, 1971). Goats had severe impacts on the Pinta ecosystem, including habitat destruction, soil erosion and overgrazing of selected plant species (Weber, 1971; Hamann, 1975). In response to this degradation, the Galápagos National Park Service and the Charles Darwin Research Station initiated an eradication programme in 1971. Vegetation recovery after goats were initially reduced in numbers was swift (Hamann, 1979; Hamann, 1993).

\section{Methods and Results}

The initial eradication programme consisted of ground hunters using 0.22 calibre rifles, with intermittent use of non-specialist dogs. Goats were hunted annually from 1971-1982, with 1-5 hunting trips per year, although effort varied (i.e. length of the stay and number of hunters; Fig. 1). Hunters first targeted females in an effort to decrease reproductive rate, and this also facilitated culling of males because males aggregate in the absence of females. During 1971-1979, 41,390 goats were killed, with 21,823 killed in 1972 alone (Fig. 1). Unfortunately no system was implemented to confirm the number of goats killed (e.g. the collecting of tails of killed goats), and numbers might have been inflated by hunters. Hunting effort peaked in 1977 (Fig. 1). After 1982 the island was visited irregularly, with hunting trips in 1985, 1987-90 and 1995-96 (Fig. 1). The island was wrongly declared goat-free in 1985 (Calvopiña, 1985). During 1988-1990 17 goats were killed and an attempt to use a single Judas goat failed because of equipment failure and/or poor personnel training. The island was again wrongly declared goat-free in 1990 (Evans, 1990). No monitoring programme to confirm eradication was implemented, with goats being shot in the last trips undertaken in both cases.

In 1999 the Galápagos National Park Service and the Charles Darwin Research Station implemented a revised eradication campaign. The revised campaign was part of a capacity building programme leading to goat eradication on Isabela Island, the largest island in the Galápagos archipelago (Isabela Project, 1997). Hunting continued to be ground-based, using 0.22 and 0.223 calibre rifles. To reduce the chance of goats escaping a hunting episode 
Table 1 Eradication effort on Pinta Island, 1999-2003. Logistic days include activities such as cutting trails and managing boats for transport, while hunter/observation days is time spent actually observing, hunting or monitoring. Judas goat days are split into the three types and the three stages: pre-eradication (prior to hunting), eradication and monitoring. Individual Judas goats were often present for more than one stage.

\begin{tabular}{lcccc}
\hline & Pre-eradication & Eradication & Post-eradication monitoring \\
& $8 / 4-19 / 5 / 1999$ & $20 / 5-30 / 7 / 1999$ & $31 / 7 / 1999-22 / 6 / 2003$ & Total \\
\hline Logistic days & 82 & 172 & 122 & 376 \\
Hunter or observation days (hours) $_{\text {Judas goat days (no. goats) }}^{2}$ & $45(385)$ & $83(558)$ & $216(1,470)^{1}$ & $344(2,413)$ \\
$\quad$ Castrated male Judas days (no. goats) & $280(13)$ & $713(23)$ & $4,786(21)$ & $5,859(27)$ \\
Male Judas days (no. goats) & $74(5)$ & $354(6)$ & $342(4)$ & $982(8)$ \\
Female Judas days (no. goats) & $0(0)$ & $72(12)$ & $4,426(14)^{3}$ & $379(5)$ \\
\hline
\end{tabular}

${ }^{1}$ Hunting dogs were used in the monitoring phase (325 dog-hours).

${ }^{2}$ Last Judas goat removed November 2000.

${ }^{3} 15$ females released, but one female goat was never relocated.

and to prevent goat wariness, hunters received training in hunting techniques, global positioning systems, and radio communications. During two hunting trips in 1999, 65 goats were killed, with none of the targeted goats escaping. Effort was comparable to peak effort during the 1970s (Fig. 1). During parts of the monitoring phase, hunters were accompanied by trained goat-hunting dogs. No goats were detected from August 1999 to June 2003, during which time there were substantial hunting/monitoring efforts (Fig. 1, Table 1).

In addition to hunting, Judas goats were used to locate the remaining goats and as the primary monitoring tool (Taylor \& Katahira, 1988; Campbell, 2002). In 1999-2000 28 Judas goats equipped with telemetry collars (Sirtrack Limited, Havelock North, New Zealand) were placed on the island, in the hope that collared goats would associate with others. Judas goats were transported from other islands (Santiago and Santa Cruz Islands, Galápagos) to avoid increasing wariness of Pinta goats during initial capture attempts. A quarantine programme ( $>7$ days) reduced the risk of transporting seeds or parasites. Hunters located collared Judas goats regularly over an 18-month period (1999-2000) and removed any associated goats.

As part of a larger project to assess Judas goat techniques (Campbell, 2002), three types of Judas goats were used: eight castrated males, five intact males and 15 females. The three groups performed differently in terms of the number of goats associated with them during their tenure on the island (mean $\pm \mathrm{SD}$ : females $2.8 \pm 5.9$; intact males $14.5 \pm 7.8$; castrated males $1.7 \pm 2.6$ ). Intact males performed better than castrated males while controlling for the total amount of days present on the island (number of goats associated $\pm \mathrm{SD}$ : intact males $11.6 \pm 9.3$; castrated males $1.7 \pm 2.6$; ANCOVA $F_{1,8}=7.67, \mathrm{P}=0.01$, covariate is total days on island). Statistical inference between females and males was confounded because the majority of male Judas goats were on the island before and during the 1999 hunting effort, while the majority of females were present after the 1999 hunting effort and during the monitoring phase (Table 1). There was no difference between the three groups in number of days to associate with goats after release; however, statistical power was low (ANOVA $F_{2,24}=0.99, \mathrm{P}=0.386$; power analysis $1-\mathrm{B}=0.47$, effect size $=0.25$; Cohen, 1977).

In October 2003 the Galápagos National Park initiated a systematic search for possible remaining tortoises on Pinta Island, incorporated into the regular goat monitoring effort. This substantial effort (180 hunter-days, 1,260 search hours) consisted of systematic searching using equidistant points throughout the entire island, concentrating on vegetated sections and high quality tortoise habitat. While the remains of fifteen tortoises were found, no live animals were located. However, the search revealed a single male goat. Based on its colour and brown markings the goat is almost certainly a reintroduction, rather than from the original eradicated population (which were black with some white markings). The goat was subsequently shot.

This animal confirmed reports from 2000 and 2003 that fishermen had released and later sighted goats. A similar situation occurred on nearby Marchena Island; after being goat-free for more than 30 years, recent reintroductions have been documented and several animals eliminated since 2000.

\section{Discussion}

Pinta Island is now free of goats. For the first time in $>50$ years the island is free of introduced mammals, setting the stage for future restoration such as the potential reintroduction of Galápagos tortoises (Hamann, 1993). While goats have been eradicated from 15 larger islands (e.g. San Clemente, USA; Espanola, Galápagos; and Auckland, New Zealand), Pinta is the largest successful eradication in terms of goats removed (Hoeck, 1984; 
Keegan et al., 1994; Chimera et al., 1995). On San Clemente Island (14,800 ha) approximately 29,000 goats were removed over a 20-year period using both aerial and ground-based methods (Keegan et al., 1994), compared to 41,682 from Pinta.

Judas goat techniques proved critical in locating the last goats, as well as a monitoring tool to confirm eradication (Rainbolt \& Coblentz, 1999). While only 28 individual Judas goats were used, results suggest that intact males may outperform castrated males. While it is difficult to compare the performance of female Judas goats in this study, in certain situations females may outperform males (e.g. females in oestrus). Females outperforming males has been reported elsewhere (Taylor \& Katahira, 1988). Recently developed techniques of sterilization and hormone therapy will probably improve the efficacy of female Judas goats (Campbell, 2002).

The implementation of a monitoring programme is a requisite for a successful eradication. If such a programme had been in place in the early 1980s, and effort had been increased rather than decreased when goats became rare (Fig. 1), goats would probably have been eradicated from the island much earlier. The majority of goats were removed in the first 10 years of the eradication campaign. After 20 years of intermittent trips to the island and the island being twice incorrectly declared goat-free, a revised campaign in 1999 removed the remaining goats within 1 year. Managers had earlier relied on verbal confirmation from hunters that no goats remained rather than on a systematic monitoring programme for any remaining individuals. The earlier eradication failures were not due to a lack of funding but solely to the lack of monitoring. This is in contrast to other past Galápagos eradication projects where lack of manager confidence leading to restricted funding caused eradication failure (e.g. introduced rats Rattus rattus on Pinzon Island). An earlier monitoring programme would have saved money and freed up resources for other projects in the archipelago. The cost of the 1999-2003 campaign alone was US $\$ 72,000$. Costs for the earlier phases of the eradication are unfortunately not available.

The benefits of an extensive monitoring programme are also demonstrated by the detection of the single goat reintroduction in October 2003. Reintroductions after a successful eradication are not uncommon and threaten the conservation value of introduced species eradications. Regular post-eradication monitoring programmes, along with environmental education campaigns targeted toward island users such as fishermen are critical components of a successful eradication campaign (Donlan \& Keitt, 1999; Tershy et al., 2002).

While Pinta Island is now goat-free and a long-term monitoring programme is in place to prevent future reintroductions, Pinta tortoises are extinct in the wild.
The last known tortoise (Lonesome George, now in captivity) to browse on Pinta Island was in the early 1970s. The last ecologically effective population (sensu Soule et al., 2003) was probably over a century ago, and thus certain ecological interactions are now absent on the island (e.g. herbivory, seed scarification and dispersal). Previous attempts to outbreed Lonesome George with related populations have failed (Fritts et al., 2000). However, recent genetic studies provide guidance for improving the probability of success of outbreeding (Caccone et al., 1999; Burns et al., 2003). An alternative strategy would be to introduce genetically and morphologically related tortoises from other islands, thereby restoring the ecological and evolutionary processes that were lost with the extinction of Pinta tortoises. Such approaches are underway with endangered birds on islands in the tropical Pacific (Steadman \& Martin, 2003) and endangered vertebrates in the British Virgin Islands (Lazell, 2002). Whatever the approach, the successful eradication of goats from Pinta Island provides an ecosystem suitable for tortoise restoration.

Introduced mammals are now being removed from larger and more biologically complex islands (Veitch \& Clout, 2002; Donlan \& Comendant, 2003; Donlan et al., 2003). With larger islands, efficient eradication techniques when animals are at low densities, as well as monitoring programmes, will be central to success. Capacity building, along with the revised hunting and monitoring techniques used on Pinta, is leading to more ambitious eradication projects in the Galápagos Archipelago. On Santiago Island (58,465 ha), feral pigs Sus scrofa have been eradicated, while goats and donkeys Equus asinus are currently being removed (Cruz et al., in press), and the eradication of goats is underway on the much larger Isabela Island (458,812 ha). Improved technology, efficient techniques, and extensive monitoring programmes will play critical roles in these projects. Given limited resources, new eradication programmes should strive to increase eradication efficiency and learn from past campaigns. Nowhere but on islands is extinction so rife, and we cannot afford to spend decades removing introduced mammals from islands.

\section{Acknowledgements}

This publication is a result of GEF Project ECU/00/G31 Invasive Species of the Galápagos in collaboration with the Charles Darwin Foundation for the Galápagos Islands and the Galápagos National Park Service. We express our gratitude to all the hunters who made this conservation action possible. We thank Linda Cayot and the participants of the 1997 workshop Feral Goat Eradication Program for Isla Isabela for their foresight in weaving the Pinta campaign into the capacity building phase of 
Proyecto Isabela. Howard Snell and the University of New Mexico provided technical assistance in the form of maps for GIS applications, and the equidistant GPS point system. T. Comendant improved an earlier version of this manuscript. B. Coblentz and an anonymous reviewer improved this manuscript. Funding for the 1999-2003 campaign was provided by the Global Environment Facility, Charles Darwin Foundation, Inc., Galápagos National Park Service and the Charles Darwin Foundation. TAME provided reduced fares between the mainland and archipelago.

\section{References}

Burns, C.E., Ciofi, C., Beheregaray, L.B., Fritts, T.H., Gibbs, J.P., Márquez, C., Milinkovitch, M.C., Powell, J.R. \& Caccone, A. (2003) The origin of captive Galápagos tortoises based on DNA analysis: implications for the management of natural populations. Animal Conservation, 6, 329-337.

Caccone, A., Gibbs, J.P., Ketmaier, V., Suatoni, E. \& Powell, J.R. (1999) Origin and evolutionary relationships of giant Galápagos tortoises. Proceedings of the National Academy of Sciences of the United States of America, 96, 13223-13228.

Calvopiña, L. (1985) Annual Report of the Charles Darwin Research Station 1984-1985. Department of Introduced Mammals, Quito, Ecuador.

Campbell, K.J. (2002) Advances in Judas goat methodology in the Galápagos Islands: manipulating the animals. In Judas Workshop 2002 (eds J. Gregory, B. Kyle \& M. Simmons), pp. 70-77. Otago Conservancy, Dunedin, New Zealand.

Ceballos, G. \& Brown, J.H. (1995) Global patterns of mammalian diversity, endemism, and endangerment. Conservation Biology, 9, 559-568.

Chimera, C., Coleman, M.C. \& Parkes, J.P. (1995) Diet of feral goats and feral pigs on Auckland Island, New Zealand. New Zealand Journal of Ecology, 19, 203-207.

Coblentz, B.E. (1978) The effects of feral goats (Capra hircus) on island ecosystems. Biological Conservation, 13, 279-285.

Cohen, J. (1977) Statistical Power Analysis for the Behavioral Sciences. Academic Press, New York, USA.

Cruz, J.B. \& Cruz, F. (1987) Conservation of the dark rumped petrel (Pterodroma phaeopygia) in the Galápagos Islands, Ecuador. Biological Conservation, 42, 303-312.

Cruz, F., Donlan, C.J., Campbell, K. \& Carrion, V. (in press) Conservation action in the Galápagos: feral pig (Sus scrofa) eradication from Santiago Island. Biological Conservation.

Daltry, J.C., Bloxam, Q., Cooper, G., Day, M.L., Hartley, J., Henry, M., Lindsay, K. \& Smith, B.E. (2001) Five years of conserving the 'world's rarest snake', the Antiguan racer Alsophis antiguae. Oryx, 35, 119-127.

Daly, K. (1989). Eradication of feral goats from small islands. Oryx, 23, 71-75.

Davis, S.D., Droop, S.J.M., Gregerson, P., Leon, C.J., Vila-Lobos, J.L., Synge, H. \& Zantovska, J. (1986) Plants in Danger: What Do We Know? IUCN, Gland, Switzerland.

Desender, K., Baert, L., Maelfait, J.-P. \& Verdyck, P. (1999) Conservation on Volcan Alcedo (Galápagos): terrestrial invertebrates and the impact of introduced feral goats. Biological Conservation, 87, 303-310.

de Vries, T. (1984) The giant tortoises: a natural history disturbed by man. In Key Environments. Galápagos (ed. R. Perry), pp. 145-156. Pergamon Press, Oxford, UK.
Diamond, J.M. (1989) Overview of recent extinctions. In Conservation for the Twenty-first Century (eds D. Western \& M.C. Pearl), pp. 37-41. Oxford University Press, New York, USA

Donlan, C.J. \& Keitt, B.S. (1999) Using research and education to prevent extinction. California Coast and Ocean, 15, 20-23.

Donlan, C.J. \& Comendant, T. (2003) Getting rid of rats. E/The Environmental Magazine, September, 10.

Donlan, C.J., Tershy, B.R., Campbell, K. \& Cruz, F. (2003) Research for requiems: the need for more collaborative action. Conservation Biology, 17, 1-2.

Ebenhard, T. (1988) Introduced birds and mammals and their ecological effects. Swedish Wildlife Research Viltrevy, 13, 1-107.

Elton, C.S. (1958) The Ecology of Invasions by Animals and Plants. Methuen, London, UK.

Evans, D. (1990) Informe del Director. Reunión del Consejo Ejecutivo de la Fundación Charles Darwin, Quito, Ecuador.

Fritts, T.H., Snell, H.L., Cayot, L., MacFarland, C., Earsom, S., Marquez, W., Llerena, W. \& Llerena, F. (2000) Progress and priorities in research for the conservation of reptiles. In Science for Conservation in the Galápagos, vol. 39-48 (ed. N. Sitwell). Institut Royal des Sciences Naturelles de Belgique, Brussels, Belgium.

Groombridge, B. (1992) Global Biodiversity: Status of the Earth's Living Resources: A Report. Chapman \& Hall, London, UK.

Hamann, O. (1975) Vegetational changes in the Galápagos Islands during the period 1966-73. Biological Conservation, 7, 37-59.

Hamann, O. (1979) Regeneration of vegetation on Santa Fé and Pinta Islands, Galápagos, after the eradication of goats. Biological Conservation, 15, 215-236.

Hamann, O. (1981) Plant communities of the Galápagos Islands. Dansk Botanisk Arkiv, 34, 1-163.

Hamann, O. (1993) On vegetation recovery, goats and giant tortoises on Pinta Island, Galápagos, Ecuador. Biodiversity and Conservation, 2, 138-151.

Hoeck, H.N. (1984) Introduced fauna. In Key Environments: Galápagos (ed. R. Perry), pp. 233-246. Pergamon Press, Oxford, UK.

Isabela Project (1997) Plan for the Protection of Northern Isabela Island, Galápagos National Park, Ecuador from Ecosystem Damage caused by Feral Ungulates. Unpublished Report. Charles Darwin Research Station/Galápagos National Park Service, Puerto Ayora, Santa Cruz, Galápagos Islands.

Keegan, D.R., Coblentz, B.E. \& Winchell, C.S. (1994) Feral goat eradication of San Clemente Island, California. Wildife Society Bulletin, 22, 56-61.

King, W. (1985) Island birds: will the future repeat the past? In Conservation of Island Birds: Case Studies for the Management of Threatened Island Birds (ed. P.J. Moors), pp. 3-16. International Council for Bird Preservation, Cambridge, UK.

Lazell, J. (2002) Restoring vertebrate animals in the British Virgin Islands. Ecological Restoration, 20, 179-185.

MacPhee, R.D.E. \& Flemming, C. (1999) Requim AEternam: the last five hundred years of mammalian species extinctions. In Extinctions in Near Time: Causes, Contexts, and Consequences (ed. R.D.E. MacPhee), pp. 333-371. Kluwer Publishing, New York, USA.

Moran, R. (1996) The flora of Guadalupe Island, Mexico. Memoirs of the California Academy of Sciences, 19, 1-190.

Pritchard, P.C.H. (1984) Further thoughts on "Lonesome George". Noticias de Galápagos, 39, 20-23.

Rainbolt, R.E. \& Coblentz, B.E. (1999) Restoration of insular ecosystems: control of feral goats on Aldabra Atoll, Republic of Seychelles. Biological Invasions, 1, 363-375. 
Schofield, E.K. (1989) Effects of introduced plants and animals on island vegetation: examples from the Galápagos Archipelago, Ecuador. Conservation Biology, 3, 227-238.

Simberloff, D. (2001) Eradication of island invasives: practical actions and results achieved. Trends in Ecology \& Evolution, 16, 273-274.

Snell, H.M., Stone, P.A. \& Snell, H.L. (1995) Geographical characteristics of the Galápagos Islands. Noticias de Galápagos, $55,18-24$.

Soule, M.E., Estes, J.A., Berger, J. \& Del Rio, C.M. (2003) Ecological effectiveness: conservation goals for interactive species. Conservation Biology, 17, 1238-1250.

Steadman, D.W. \& Martin, P.S. (2003) The late Quaternary extinction and future resurrection of birds on Pacific islands. Earth-Science Reviews, 61, 133-147.

Taylor, D. \& Katahira, L. (1988) Radio telemetry as an aid in eradicating remnant feral goats. Wildlife Society Bulletin, 16, 297-299.

Tershy, B.R., Donlan, C.J., Keitt, B., Croll, D., Sanchez, J.A., Wood, B., Hermosillo, M.A. \& Howald, G. (2002) Island conservation in northwest Mexico: a conservation model integrating research, education and exotic mammal eradication. In Turning the Tide: the Eradication of Invasive Species (eds C.R. Veitch \& M.N. Clout), pp. 293-300. IUCN Species Survival Commission Invasive Species Specialist Group, Gland, Switzerland.

Van Denburgh, J. (1914) Expedition of the California Academy of Sciences to the Galápagos Islands, 1905-1906. The gigantic land tortoises of the Galápagos Archipelago. Proceedings of the California Academy of Sciences, Fourth Series, 2, 203-374.
Veitch, C.R. \& Clout, M.N. (2002) Turning the Tide: the Eradication of Invasive Species. IUCN, Gland, Switzerland.

Weber, D. (1971) Pinta, Galápagos: Une ile a sauver. Biological Conservation, 4, 8-12.

\section{Biographical sketches}

Karl Campbell is Field Operation Specialist for the Isabela Project with the Galápagos National Park and Charles Darwin Foundation. He is developing improved Judas goat techniques.

Josh Donlan's research interests include species interactions, the role of ecological history in conservation, and the removal of introduced species on islands in the Americas.

Felipe Cruz is Technical Director of the Isabela Project and has over 22 years of experience on the Galápagos, including tenure as deputy director of Galápagos National Park. His research interests include seabird ecology and the eradication of introduced mammals.

Victor Carrion is head of the Control and Eradication Unit at the Galápagos National Park and has 10 years of experience with the Galápagos National Park, managing introduced vertebrates, as well as researching and implementing eradication techniques. 